\title{
ISRU Soil Mechanics Vacuum Facility: Soil Bin Preparation and Simulant Strength Characterization
}

\author{
Julie Kleinhenz $^{1}$ and Allen Wilkinson ${ }^{2}$ \\ NASA Glenn Research Center, Cleveland, Ohio, 44135
}

\begin{abstract}
Testing in relevant environments is key to exploration mission hardware development. This is true on both the component level (in early development) and system level (in late development stages). During ISRU missions the hardware will interface with the soil (digging, roving, etc) in a vacuum environment. A relevant test environment will therefore involve a vacuum chamber with a controlled, conditioned simulant bed. However, in earthbased granular media, such as lunar soil simulant, gases trapped within the material pore structures and water adsorbed to all particle surfaces will release when exposed to vacuum. Early vacuum testing has shown that this gas release can occur violently, which loosens and weakens the simulant, altering the consolidation state.
\end{abstract}

The Vacuum Facility \#13, a mid-size chamber $(3.66 \mathrm{~m}$ tall, $1.5 \mathrm{~m}$ inner diameter) at the NASA Glenn Research Center has been modified to create a soil mechanics test facility. A $0.64 \mathrm{~m}$ deep by $0.914 \mathrm{~m}$ square metric ton bed of lunar simulant was placed under vacuum using a variety of pumping techniques. Both GRC-3 and LHT-3M simulant types have been used. An electric cone penetrometer was used to measure simulant strength properties at vacuum including: cohesion, friction angle, bulk density and shear modulus. Simulant disruptions, caused by off gassing, affected the strength properties, but could be mitigated by reducing pump rate. No disruptions were observed at pressures below $2.5 \mathrm{~T}$ orr, regardless of the pump rate. However, slow off gassing of the soil lead to long test times, a full week, to reach $10^{-5}$ Torr. This work highlights the need for robotic machine-simulant hardware and operations in vacuum to expeditiously perform (sub-)systems tests.

\section{Nomenclature}

$\begin{array}{ll}C P & =\text { Cone Penetrometer } \\ V F & =\text { Vacuum Facility } \\ R G A & =\text { Residual Gas Analyzer }\end{array}$

\section{Introduction}

$\mathrm{T}$

HE exploration of extraterrestrial environments requires rugged hardware that can survive a variety of harsh conditions. Extraterrestrial environments have damaged or ended the life of all moving machines within two years. The longest living machines have been simple compared to hard working surface systems of the future. For In-Situ Resource Utilization (ISRU) applications, this hardware involves a variety of relatively complex systems, such as excavators, drills, granular reactors, hoppers, augers, crushers, sifters, mixers, etc. Ground based testing in relevant environments is therefore key to exploration mission hardware development. This is true on both the component level (in early development) and system level (in late development stages).

Relevant environment testing has been limited thus far. Physical regolith simulants are in widespread use to explore various abrasion (wear), traction (force), adhesion, flow, etc., effects. Pressure and temperature also play a critical role in hardware performance. This includes changes to the simulant geotechnical properties in addition to

\footnotetext{
${ }^{1}$ Research Engineer, Propellants and Propulsion Branch, MS 301-3 21000 Brookpark Road, Cleveland, OH 44135, Senior Member.

${ }^{2}$ Research Scientist, Fluid Physics and Transport Branch, MS 110-3, Non-member.
} 
electrical and mechanical hardware effects. A relevant test environment will therefore involve a vacuum chamber with a conditioned simulant bed (a known/controlled consolidation state). However, in earth-based granular media, such as lunar regolith simulant, gases trapped within the material pore structures and water adsorbed on all particle surfaces are released when exposed to vacuum. Early vacuum testing has shown that this gas release can occur violently, which loosens and weakens the simulant, altering the consolidation state. A relevant pressure test facility must be equipped to mitigate this occurrence and/or find a way to remotely condition the simulant after the vacuum environment has been achieved.

The Vacuum Facility (VF) \#13, a mid-size chamber (3.66m (tall, 1.5m (5ft) inner diameter) at the NASA Glenn Research Center, has been modified to create such a soil mechanics test facility. Using a 1 ton bin of simulant, tests were performed to explore the simulant-pressure interaction. This includes identifying the conditions that create the simulant disturbances and exploring options for mitigation. The goal was to reach a $10^{-4}$ to $10^{-7}$ Torr vacuum, similar to that used in past published terrestrial simulant work ${ }^{1}$. The actual lunar surface pressure ranges from $10^{-7}$ to $10^{-12}$ Torr, depending on ascent and landing exhaust gases in the moon's atmosphere ${ }^{2}$. However, large $10^{-12}$ Torr vacuum facilities are not affordable at this time. Once at vacuum, the simulant strength was characterized as a function of depth and location using a cone penetrometer (CP), which is the most common and trusted terrestrial tool for its simplicity and repeatability. A residual gas analyzer (RGA) was employed to determine the composition of the released gases. Various facility and procedural improvements were explored to improve the evacuation process. A total of three tests were performed during phase 1 of the test program; two with GRC-3 lunar geotechnical simulant and one with lunar highlands analog LHT-3M simulant. Phase 2 of the program will incorporate a means of robotic simulant tilling and compaction that can be used after vacuum is achieved. Phase 2 commenced in November 2011.

The overall goals of this effort are to demonstrate the capability of achieving a credible lunar simulant vacuum test environment large enough for subsystem testing and to establish the robotic operations that create a well characterized controlled soil bed. With this system one can condition a regolith bed, measure the in-situ soil strength, perform a geotechnical test (e.g. traction, excavation) on hardware, and compare model predictions with the measured performance, all in an extra-terrestrially realistic environment.

\section{Hardware}

The vacuum facility (VF-13) is a vertical, cylindrical chamber with and internal volume of $6.35 \mathrm{~m}^{3}$ (Fig1A). The bulk of the volume is within the removable $2.52 \mathrm{~m}$ tall by $1.5 \mathrm{~m}$ diameter lid. The fixed base is $1.08 \mathrm{~m}$ deep and accommodates all the electrical, mechanical, and gas feed-throughs. Three different types of pumps were used to achieve the target pressure. A venturi pump was used during the initial pump down and has an operating range of 760 to around 100 Torr. Since this pump has no moving parts, it is not sensitive to dust or water. The primary roughing pump on the facility is a rotary vacuum pump which has a range of 760 to 0.1 Torr. A portable rotary vane roughing pump was also added to increase pump rate in this range. These pumps are sensitive to contamination from the simulant, therefore some additional precautions were taken. On the primary pump line, a $1.8 \mathrm{~m}$ tall upside down u-tube trap was added to encourage particle elutriation. A non-immersion vacuum oil trap was also located at its downstream end to catch any particles inertially before they could travel horizontally to the pump. This was a followed by a fabric particle filter and cold trap at the pump inlet. While a cold trap is traditionally used to prevent backflow of oil from the pump, here it acted as a water trap. Once the chamber pressure reached 0.1 Torr, the cryogenic pump could be used. This pump is capable of achieving pressures on the order of $10^{-7}$ Torr in VF-13.

The test specific hardware is shown in Fig.1B (with the VF13 lid removed). The simulant bin is a $\sim 1 \mathrm{~m}^{2}$ by $0.7 \mathrm{~m}$ deep box that contains roughly 1 metric ton of lunar regolith simulant. The soil depth was approximately $0.6 \mathrm{~m}$, which would be adequate for hardware tests regarding traction and surface excavation. The first set of tests used GRC-3 lunar geotechnical simulant (a sand and silt mix), while the latter tests used NU-LHT-3M (a lower cost formulation of LHT-2M, without the trace minerals and agglutinates). The tall vertical structure in Fig.1B is the CP system, which was driven by a standard hand drill via a flexible shaft feed-though coupled to the jackscrew drive. The jackscrew

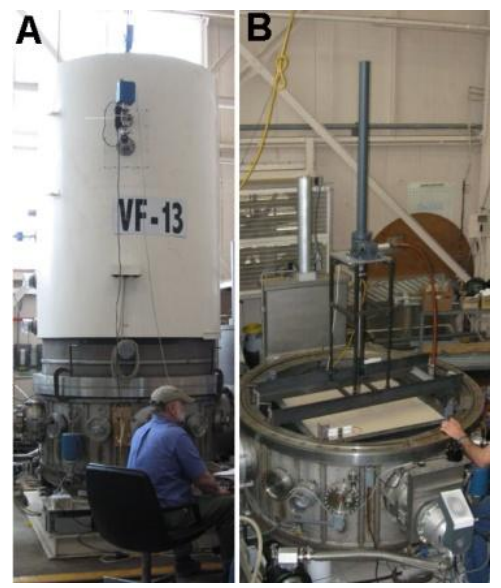

Figure 1: Photo of the vacuum facility (A) with the lid and (B) without the lid, showing the research hardware. The tall structure is the cone penetrometer. 
pushed the $\mathrm{CP}$ at a constant $1 \mathrm{~cm} / \mathrm{sec}$ into the simulant. The pressure felt by the tip during penetration was recorded at $2-5 \mathrm{~mm}$ depth intervals. All lubricated surfaces of the drive system were cleaned of stock lubricants and relubricated with a specialty vacuum compatible lubricant. Three cameras were mounted within the chamber to monitor simulant disturbances during the pump down. The cameras were modified with additional heat sinks to ensure operation at low pressure. Two were located at opposite corners of the simulant bin, only a few inches off the simulant surface for a grazing view. The third was mounted on the $\mathrm{CP}$ frame to give a top view of the bin surface. Pressure data was logged at $1 \mathrm{~Hz}$ over the entire test duration using a multi-mode pressure gauge. An RGA was mounted on the lid of the chamber (blue box visible in Fig.1A), with the sensor recessed behind a valve to prevent exposure to dust. The RGA could not be activated until the pressure reached $5 \times 10^{-4}$ Torr.

\section{Results}

\section{A. Pressure}

Figure 2 shows the pressure traces during the pump down process for all three tests. The pumps had to be shut down or operated in restricted capacity during the overnight periods, which accounts for most of the pressure rises. When the tank was allowed to sit idle with all pumps deactivated, the simulant off gassed to an equilibrium level. Once at equilibrium, the pressure stabilized; there was no evidence of chamber leakage. This can be seen in the overnight periods, particularly in tests 2 , which appear as saw tooth shapes in Fig. 2. This off gassing of the simulant resulted in long operational times; these tests were run for a full week or more. The progress was particularly slow in the $<1$ Torr range, when the roughing pumps approached the limits of their capacity. In tests 1 and 2 , the roughing pumps were unable to achieve the cryogenic pump operating pressure (0.1Torr) within a reasonable time frame. Whereas in Test 3, the cryogenic pump operation was possible on Days 9 and 11, which accounts for the sharp pressure reductions. Table 1 summarizes the operating conditions of the three tests.

The improved performance of test 3 can be attributed to both the soil simulant type and the test procedure. The GRC-3 simulant in tests 1 and 2 has a significant silt

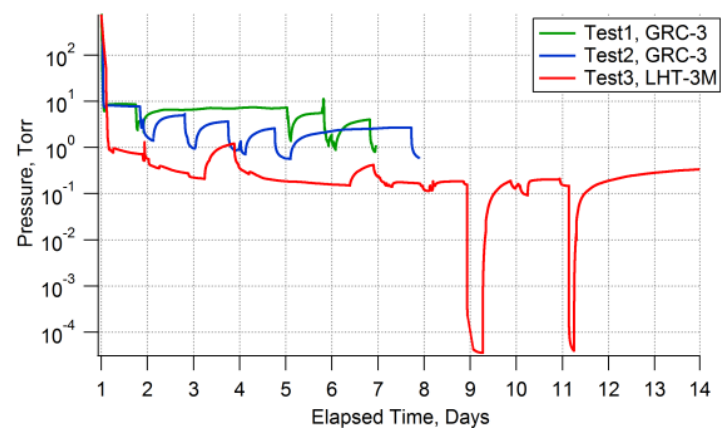

Figure 2: Time dependant pressure traces for all three tests.

The activation of the cryogenic pump resulted in a rapid pressure drop. However, this pump could not be run continuously in this test scenario. A cryogenic pump operates by freezing (condensing) gas onto a $20 \mathrm{~K}$ cold surface. When this surface becomes saturated, the pump warms and is no longer effective. Because the simulant is continuously off gassing (as opposed to an empty chamber with a finite volume of gas) the cyrogenic pump became saturated within 3 hours, resulting in reduced performance. In order to 'regenerate', or clean off the cold surface, the pump must warm to room temperature. A nitrogen purge is then used to remove the condensate. Multiple purges are necessary if the pump has been saturated. Once regenerated, it then takes 4 hours to reach the $20 \mathrm{~K}$ operating temperature. This long regeneration time is the reason that the cryogenic pump was not used on day 10. In future test series, ways of expediting the regeneration will be explored. 


\section{B. Simulant Disruptions}

Simulant disruptions can occur as gases, trapped within the simulant bed, release in a low pressure environment ${ }^{3}$. This includes gases trapped within the particle pore structure, as well volatile species (such as water) adsorbed to the particle surfaces. Several types of simulant disturbances were observed in this test series and are represented in Fig.3. Figure 3A was taken during test 2 and shows two of these disturbance types. The localized boiling shown in the foreground is characterized by small, isolated craters where the simulant appears to bubble. These are localized, small scale disturbances with little perceivable airborne dust generation. In contrast to this is the wave eruption in the image back ground. A wave eruption starts as a simulant spout (geyser) and quickly grows and propagates like a wave over the surface. A significant amount of airborne dust is generated. A crawling wave (not shown) is similar to this, but on a smaller scale and without noticeable dust generation. In these disturbances it appears as though a creature is moving just beneath the surface. A surface boil is shown in Figure 3B. This event from test 1 shows small scale disturbances over the entire surface. While a localized boil was fixed in location, these disturbances unpredictably moved over the entire surface. In this case, the surface boil evolved into a wave eruption on the right side of the image. Figure 3C, from test 3, shows a post test image of a simulant spout. Spouts were observed in most tests and were always isolated to the corners of the bin. They remained fixed in location and could persist for several minutes. This was the only simulant disturbance that occurred in test 3 .
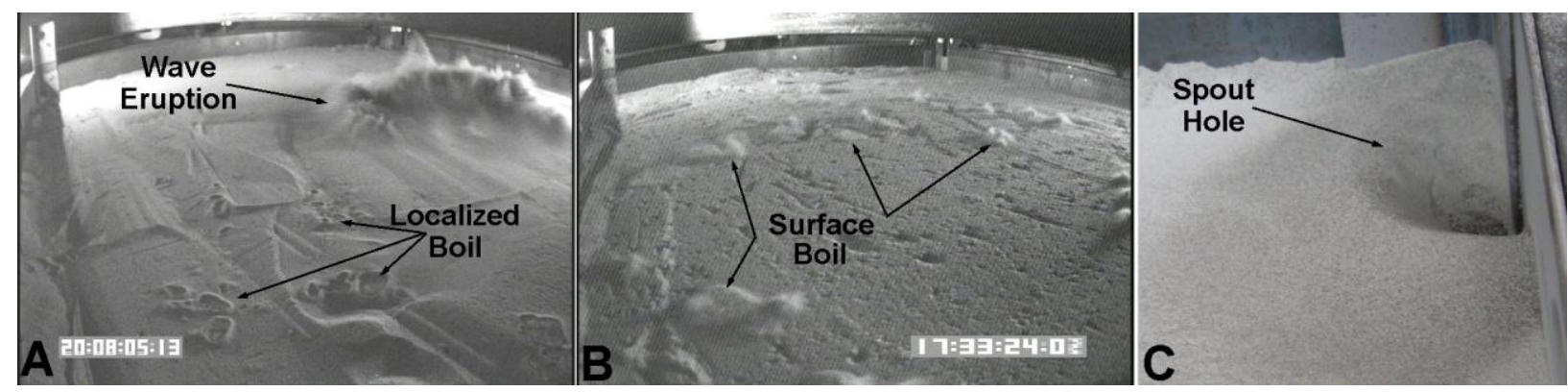

Figure 3: Photos from the video showing the different types of simulant disturbances.

Simulant disturbances were most prevalent when the pressure differential across the simulant bed was high; in other words, when the pump rate was large. This is illustrated in Fig.4, which shows the pressure log for a portion of test 1 . The pump rates displayed on the graph are approximated using a linear curve fit in the shaded regions. The two roughing pumps were initially activated concurrently, resulting in a fast pressure decline and a wave eruption simulant disturbance. As soon as the disturbance was observed, the primary rough pump was closed off, leaving the small, mobile pump acting alone. The pump rate slowed considerably, and the simulant stagnated. The primary pump was then reactivated using a nitrogen bleed to slow the pump rate on the chamber. This resulted in a lesser simulant disturbance (localized boiling). As the pump rate naturally decayed, the simulant calmed.

The simulant disturbance events for each test, along with the representative pump rates, are shown in Table 2 and graphically in Fig. 5. It should be noted that the actual pressure decay followed a more complex profile, more closely resembling an exponential. These linear rates are only intended as a rough quantification. There is not adequate data to determine if a rate/pressure threshold exists for simulant disturbances. Since the simulant strength profile would vary from test to test, this may also affect the number and nature of the disturbances. Nevertheless, regulating the pump rate does seem to mitigate simulant

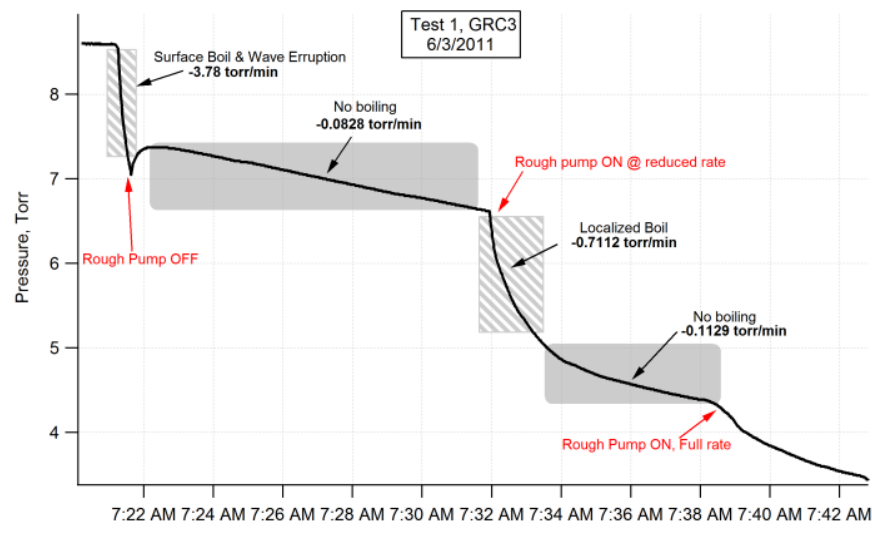

Time of Day

Figure 4: The pressure log from a portion of test 1 . The periods where simulant disturbances were observed are shown, along with pressure decay (pump down) rates based on linear curve fits of the data.

disturbance. Simulant disturbances were not observed under 2.5 Torr in any test. This includes cryogenic pump activation in test 3 which reduced the pressure from 0.15 Torr to $5 \times 10^{-4}$ Torr within $30 \mathrm{~s}$. No matter what pumping 
rate was used, there was some degree of disturbance in the 2.5 to 10 Torr range. This is a regime where the mean free path of gas molecules is similar to or somewhat larger than the size of voids in the simulant.

Table 2: Simulant disruption events for each test with the corresponding pump rate and pressure range of the event.

\begin{tabular}{|l|l|l|l|}
\hline \multirow{4}{*}{ Test 1 } & Event & $\begin{array}{l}\text { Slope, } \\
\text { Torr/min }\end{array}$ & $\begin{array}{l}\text { Pressure range, } \\
\text { Torr }\end{array}$ \\
\cline { 2 - 4 } & Spout & 307 & $754-378$ \\
\cline { 2 - 4 } & Surface boil $\rightarrow$ & -3.8 & $8.53-7.26$ \\
& Wave Eruption & & \\
\cline { 2 - 4 } Test 2 & Localized Boil & -0.7 & $6.55-5.19$ \\
\cline { 2 - 4 } & Localized spout & -53 & $293-64.5$ \\
\cline { 2 - 4 } & Localized boil & -3.6 & $25.5-15.2$ \\
\cline { 2 - 4 } & Wave Eruption & -1.4 & $7.32-6.33$ \\
\cline { 2 - 4 } & Crawling Waves & -0.2 & $6.89-4.91$ \\
& & -0.1 & $4.93-4.41$ \\
\hline Test 3 & Spout & -0.04 & $3.31-2.64$ \\
\hline & Spout & -7.0 & $50.9-15.6$ \\
\hline
\end{tabular}

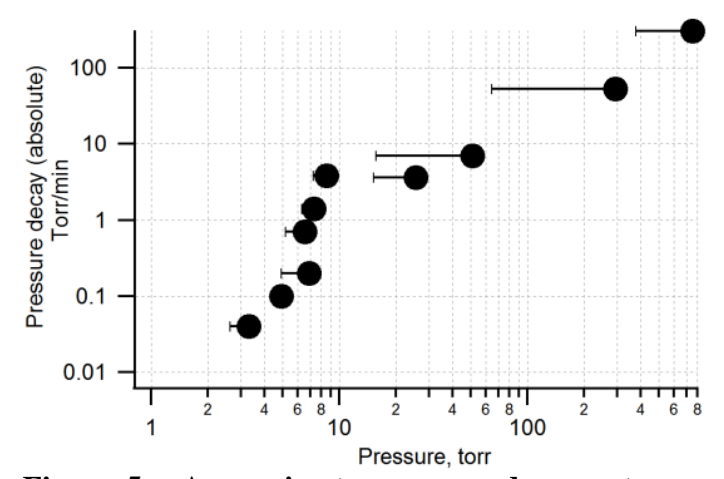

Figure 5: Approximate pressure decay rates are shown for each simulant disturbance. Rates are plotted against the pressure in which the disturbance was first observed, and error bar show

\section{Cone Penetrometer}

Cone penetrometry is perhaps the best diagnostic in use today to characterize in-situ soil strength ${ }^{4}$. NASA Glenn has developed unique computer codes which fit tip resistance versus depth data to determine simulant properties like cohesion, internal friction angle, bulk density, and bulk shear modulus in individual layers. This was based on work done by the Army Corps' Waterways Experiment Station ${ }^{5}$. This code was used on data from single cone penetrations in each of the three tests here.

Cohesion, adhesion, internal friction, wall friction, and bulk density are common parameters used in classical soil mechanics equations that predict excavation and traction forces on machines ${ }^{6}$. CP then becomes an enabler of the realistic environment testing of geotechnical systems by NASA.

The CP data seen in Figure 6 is qualitatively informative. The GRC-3 bin, used in test 1 and 2, was filled differently than the LHT-3M bin. GRC-3 was rapidly pluviated from a single 1 ton simulant bag into the bin. LHT-3M was filled by dumping many 5 gallon pails of material sequentially, with a more gentle pluviation than GRC-3. There was no tamping or consolidation done before placing either bin into the vacuum chamber. The GRC-3 traces are smoother than the LHT-3M, consistent with the more inhomogeneous filling done for LHT-3M. There was 2 months of settling of GRC-3 within the bin between tests one and two. Test 2 peaked at about 14 percent greater tip resistance than test 1 due to these time consolidation effects. LHT-3M shows about 3 times more peak strength than GRC-3. This correlates with the lack of large scale simulant disturbances, and thus less weakening,

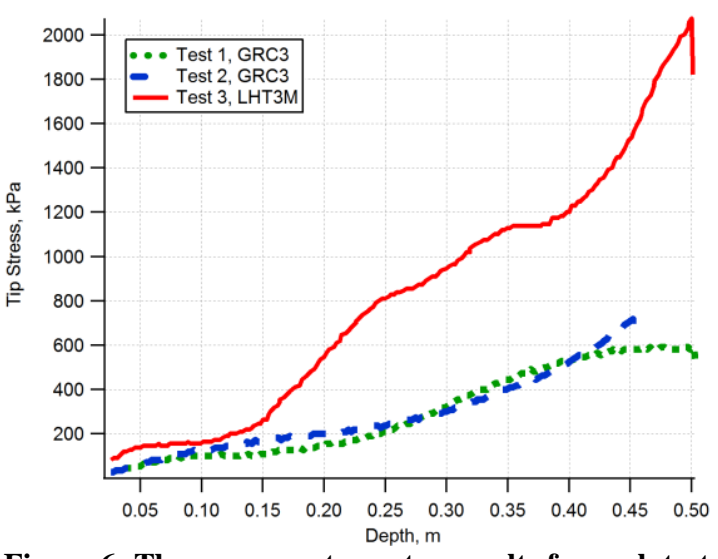

Figure 6: The cone penetrometer results for each test. of LHT-3M simulant. The LHT-3M peak tip resistance here is more than an order of magnitude smaller than has been seen in compacted lunar simulants at ambient pressure. Since the CP location was fixed, a pre-vacuum CP measurement of the un-compacted soil would have disturbed the simulant state for the vacuum measurement. These measurements are left for the next test series which will include a 2D translation system. CP measurements can then be made before and during vacuum conditions with no other consolidation actions to cause a change in simulant strength. The $2 \mathrm{D}$ translation will also provide tamper compaction capability; such that a more consolidated simulant state will be possible in the next test.

Figure 7 shows an example of the data fitting analysis using test 2 data. The blue hash marks on the $x$-axis represent layer dividers that were hypothesized based on curvature changes. Notice the shallow layer and the deep layer are concave upward and downward respectively. That often leads to reversals in the role of cohesion and 
friction angle as it affects strength, as seen in this example. Bulk density is low but equal for the layers. The bulk shear modulus is notably different with the lower layer being smaller. A piezocone could be used to obtain an independent measure of the shear modulus to check validity of what is seen here.

It is premature to draw conclusions about the effects of vacuum on simulant strength as it would affect excavation, traction, or material handling system design. Author Wilkinson is drafting a substantial review of CP data analysis tools based on Rohani \& Baladi cavity expansion-based theory and Durgunoglu \& Mitchell bearing capacity-based theory ${ }^{7}$. It is beyond the scope of this paper to develop a deeper discussion of the engineering parameter fitting presented here. It is sufficient to conclude that the parameters seen here are plausible for LHT-3M when compared to benchtop geotechnical test results at ambient conditions for bulk density, cohesion, and friction angle.

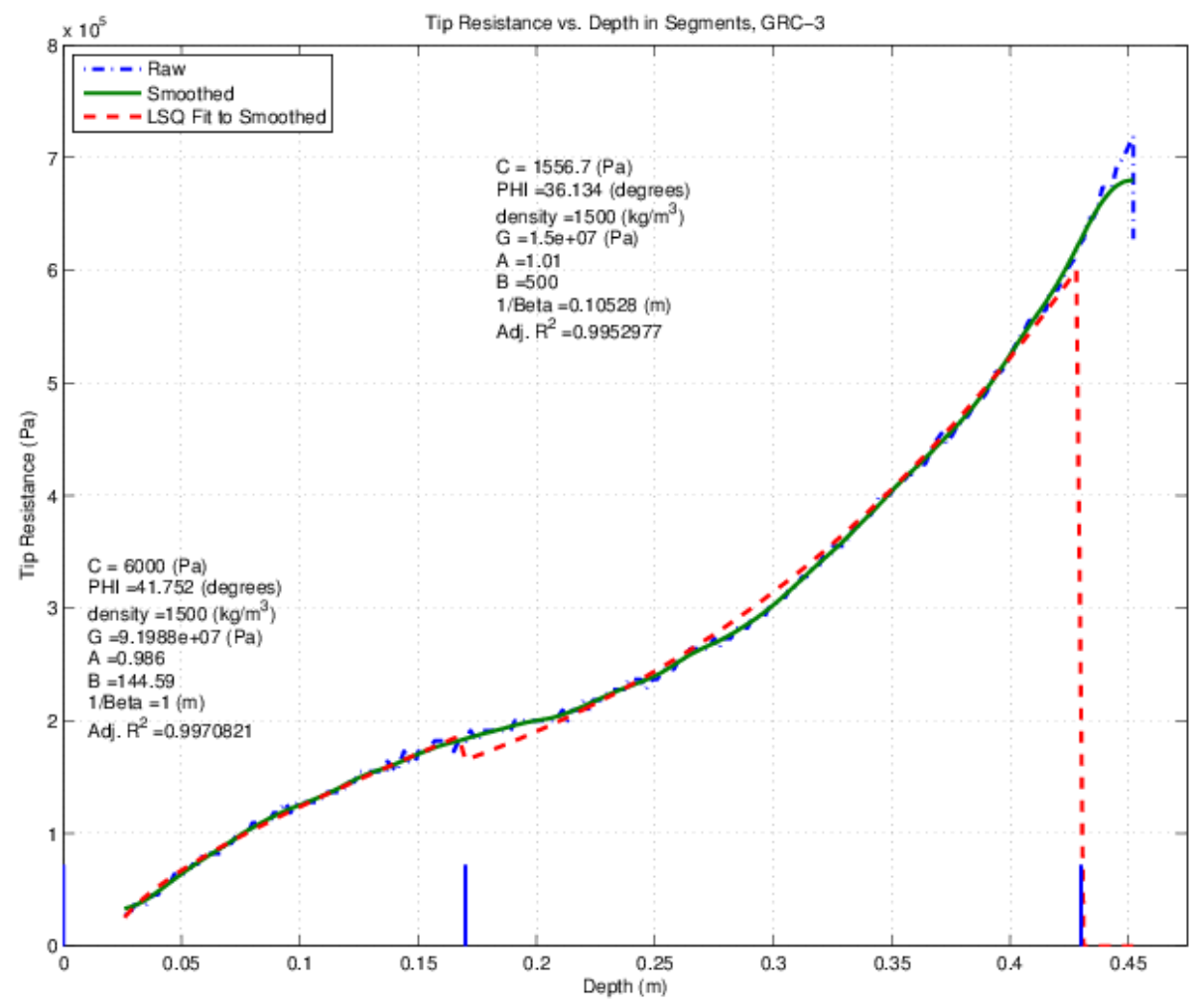

Figure 7: CP data fit to extract cohesion (C), friction angle (PHI), bulk density(density), and bulk shear modulus (G) from the several layers of GRC-3.

\section{Volatiles}

The constituents of the simulant off gassing were measured using a residual gas analyzer. Because its maximum operating pressure was $10^{-4}$ Torr, the RGA could only be used during days 9 and 11 of test 3 . The results in Fig. 8 are the average partial pressures over the two detection periods ( $4 \mathrm{hr}$ for day $9,2 \mathrm{hr}$ for day 11). These results are in line with previous, small scale tests with JSC-1a simulant ${ }^{3,8}$. The primary constituent for both days is water (mass \#18) with decomposition peaks for $\mathrm{OH}$ and $\mathrm{O}$ on either side. Lesser peaks include hydrogen and carbon dioxide, as well as nitrogen from the residual air.

The large water peak may contribute to the long pump down times. While water would likely release readily from the surface simulant, the depth gradient would be considerable. This is compounded by the small pore size of the simulant itself, which could continually trap and re-release the volatiles. Especially in the first two tests, with GRC-3 simulant, this water release from the simulant was evident. An analysis of the roughing pump oil following test 1 indicated an elevated water content. While the pretest condition of the oil is not known, the amount of water 
in the cold traps was also higher than anticipated. Over the course of test 2 more than $1300 \mathrm{ml}$ was removed from the cold traps. However, the cold trap was exposed to humid room air during periods of pump cycling. GRC-3 simulant is about 0.07 percent water, by weight (unpublished tests at GRC as per ASTM D2216). The total water content of the simulant was therefore estimated to be about $660 \mathrm{ml}$ of water, using this measurement along with three monolayers of water for each particle (which would not be included in the ASTM measurement). (The water monolayers were calculated using the measured particle size distribution ${ }^{9}$ and assuming spherical, cubic packed particles). A high water constituent does present some logistic issues for test operation. The slow volatilization of water results in longer pump down times. The water also presents a concern to operation of both the roughing pump (oil contamination) and the cryogenic pump (saturation of the cold surface). Mitigation techniques could include soil tilling to expedite volatilization and a water insensitive pump system, such as a turbo pump.

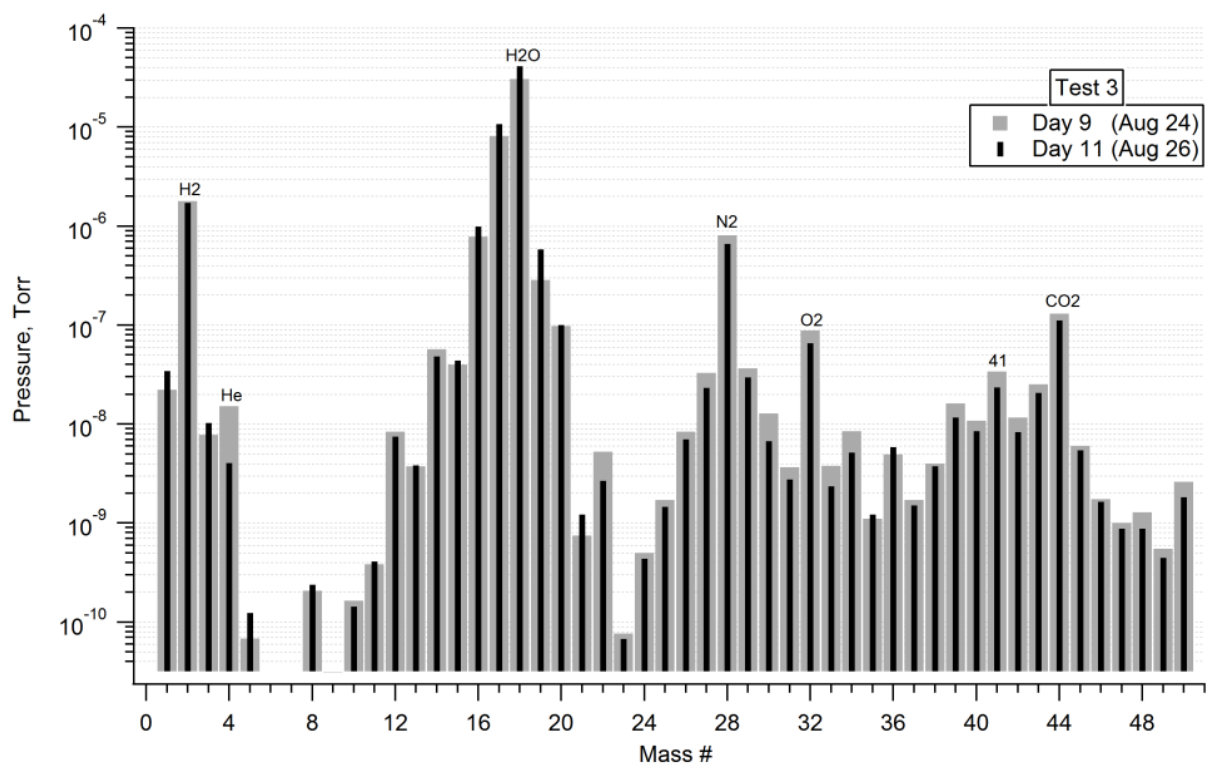

Figure 8: Results from the residual gas analyzer for test 3.

\section{Conclusion}

A set of tests were performed to explore pressure effects on lunar simulant. Previous, smaller scale simulant tests indicated that off gassing of the soil during vacuum pump down caused disruptions to the preconditioned simulant state. Prior methods for mitigating this, such as pre-drying the simulant, are not feasible for the larger scale bins that would be required for ISRU hardware testing. The goal of this initial test series was to identify the conditions that cause simulant disturbances, explore options for mitigating these disturbances, and examine logistics for these larger scale tests. As such, a vacuum chamber facility at the NASA Glenn Research Center was modified to accommodate a $\sim 1 \mathrm{~m}^{2}$ by $0.6 \mathrm{~m}$ deep simulant bed. This is largest simulant bed tested in a vacuum thus far.

Off gassing of the simulant resulted in simulant disruptions in all three tests during the roughing pump period (760 to $\sim 2$ Torr). The frequency and intensity of these were affected by the pump rate. Localized disruptions at slower pump rates may be more manageable in a system configuration, whereas the larger disruptions at rapid pump rates would harm simulant integrity. Disruptions were more prevalent in the GRC-3 simulant, whereas LHT-3M only had a highly localized disturbance. This may be attributed the higher water content of the GRC-3. No soil disruptions were observed below 2.5 Torr for any simulant, regardless of the pump rate.

Slow off-gassing of the simulant, particularly in the 1Torr range, resulted in log pump down times. This can be attributed to the permeation of the volatiles through the soil depth and small pore size of the simulant particles. Since the primary volatile species was water, as indicated by the RGA data, re-absorption onto surface particles may also contribute. The slowest portion of the pump down was in the range between 1 Torr and 0.1 Torr. The performance of the roughing pumps falls off significantly below 1 Torr. Yet, only the cryogenic pump had the capability to reach the target pressure $\left(<10^{-4}\right.$ Torr $)$, and its maximum operating pressure is 0.1 Torr. It took a full week of continuous, active pumping to achieve cryogenic pump activation.

Several facility and procedure improvements will be implemented in the second phase of this test program to expedite pump down. The first is a turbopump which will be used in the $<0.75$ Torr regime to improve pump rate. Turbopumps are highly sensitive to dust contamination, so they were initially disregarded. But, since simulant 
disruptions were not observed below 2.5 Torr, dust contamination at this level should be minimal. Baffles will be also added to the pump inlet as a precaution. Additionally, the turbopump should be able to reach at least the $10^{-4}$ Torr range. So the use of the cryogenic pump can be delayed, decreasing the likelihood of saturating the cold surface. Another improvement is the expansion of the roughing pump line diameter, which will increase the throughput. The addition of a tilling device is planned for later in the phase 2 program. An auger will be used to improve the gas release from the soil depth.

\section{Acknowledgments}

This work is supported by the Regolith and Environment Science and Oxygen and Lunar Volatile Extraction (RESOLVE) project under the Advanced Exploration Systems (AES) program.

\section{References}

${ }^{1}$ J. D. Nelson, "Environmental Effects on Engineering Properties of Simulated Lunar Soils," PhD thesis, Illinois Institute of Technology, Chicago, Illinois, 1967.

${ }^{2}$ LSB, G. H. Heiken, D. T. Vaniman, and B. M. French, Lunar Sourcebook: A User's Guide to the Moon.. New York: Cambridge University Press, 1991

${ }^{3}$ Shaw, K., "Post Test Summary Report JSC1-a Facility Assessment Testing", NASA GRC White paper, 2009.

${ }^{4}$ T. Lunne, P. Robertson, and J. Powell, Cone penetration testing in geotechnical practice. New York: Spon Press, 1997. and P. Mayne, "Regional report for North America," 2nd International Symposium on Cone Penetration Testing: May 2010.

${ }^{5}$ B. Rohani and G. Y. Baladi, Correlation of Mobility Cone Index with Fundamental Engineering Properties of Soil, Vicksburg, MS: Army Corps of Engineers, Waterways Experiment Station, 1981.

${ }^{6}$ A. Wilkinson and A. DeGennaro, "Digging and pushing lunar regolith: Classical soil mechanics and the forces needed for excavation and traction," Journal of Terramechanics, vol. 44, iss. 2, pp. 133-152, Apr. 2007.

${ }^{7}$ T. H. Durgunoglu and J. K. Mitchell, "Static Penetration Resistance of soils," University of California, Berkeley, Grant Report NASA-CR-133460; SSL-SER-14-ISSUE-24, 1973.

${ }^{8}$ J.R. Gaier, "Residual Gas Analysis During Thermal Control Surface Testing in the Lunar Dust Adhesion Bell Jar", Poster, Central Regional Meeting American Chemical Society, May 20-23, 2009.

${ }^{9}$ X. Zeng, C. He, and A. Wilkinson, "Geotechnical Properties of NU-LHT-2M Lunar Highland Simulant," Journal of Aerospace Engineering, vol. 23, iss. 4, pp. 213-218, Oct. 2010. 